\title{
A geometric study of different curves for the rotor profiles of a twin-screw compressor
}

\author{
Antonio Giuffrida* \\ Politecnico di Milano - Dipartimento di Energia, Via R. Lambruschini 4, 20156 Milano, Italy
}

\begin{abstract}
This paper presents the results of comparisons among some patented solutions for profiling the contours of the rotors in twin-screw compressors. Referring to a base case where all the generating curves are circumferences, patents suggesting to replace arcs of circumference with arcs of conic sections, i.e. parabola, ellipse and hyperbola, but even a straight line segment, are presented and guidelines for rotor profile construction are reported. After setting the size of the compressor, attention is paid to the inter-lobe area, as the sum of the area between two consecutive lobes in the male rotor and of the area of the groove in the female rotor. Actually, this area is strictly related to the volume displacement. Limited to the current case study, the profile including an elliptic segment seems to be the preferable solution for higher inter-lobe area, then for higher displacement, though a number of considerations should be necessary for a broader context.
\end{abstract}

\section{Introduction}

Compressors are mechanical devices used to raise the pressure of gases or vapours. Though similar to pumps, the volumetric flow rate delivered by a compressor reduces from inlet to outlet, as gases or vapours are compressible fluids. There are dynamic- and positive-displacement-type compressors. In particular, the twin-screw compressor is a positive-displacement rotary machine where two helically lobed rotors rotate within a fixed housing, as sketched in Fig. 1. This compressor has no suction or discharge valves and no clearance volume. Besides, a correct arrangement of port timing results in the built-in volume ratio of the compressor [1].

\subsection{Bibliographic survey}

Literature is rich of works dealing with screw compressors from both theoretical and experimental points of view. Two interesting review works can be referred here as concerns mathematical models for performance calculation [2] and experimental researches [3], respectively. Rotor profile shapes and machining precision affect both performance and efficiency. Focusing on the methods for generating the rotor profiles, three solutions are detailed in literature: (i) generation from a given curve on one rotor $[4,5]$, (ii) generation from a meshing line $[6,7]$ and (iii) generation from a rack $[5,8,9]$. The first method is a

\footnotetext{
${ }^{*}$ Corresponding author: antonio.giuffrida@polimi.it
} 
prevalent practice, as reported in a number of patents [10-17], dealing with primary curves on one rotor, generating conjugate curves on the other one. Any curve can be used as the primary one, but the circumference is the most common [10-12]. Nevertheless, arcs of other conic sections, namely arcs of parabola [13], ellipse [14] and hyperbola [15], but even a straight line segment [16], can be used to replace arcs of circumference. As a matter of fact, the generation method starting from a curve defined on one rotor is older than the other two [6-9], but it is a still current methodology if one considers the recent application by a German manufacturer [17].

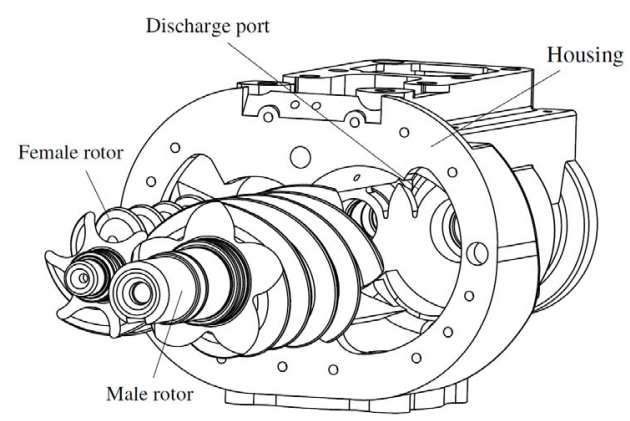

Fig. 1. Exploded view of a twin-screw compressor with particular reference to male and female rotors, housing and details of the discharge port [7].

\subsection{Objective of the work}

This paper follows a previous work oriented to calculate the main geometric characteristics of twin-screw compressors [18]. According to the actual size of a machine for compressed air application, after setting the lobe numbers in the male and female rotors (4 and 6, respectively), the inner and outer diameters of both rotors, the center distance between the rotors, the axial length as well as the wrap angle (see Table 1), this paper aims at comparing different patented frames [13-16] for the highest inter-lobe area, then the highest volume displacement.

Actually, a review of patents dealing with twin-screw compressors has been reported by Stosic et al. [5], outlining a number of cases. Nevertheless, neither Stosic et al. [5] nor other literature works thoroughly present numerical comparisons of specific case studies. This work focuses on the largest possible inter-lobe area, considering the same axial rotor length and the same wrap angle. In detail, neither a revision of the lobe numbers in the rotors, nor an increase in the rotor profile depth has been considered. The first solution may be trivial, as a $3 / 5$ configuration [19-21], i.e. 3 lobes in the male rotor and 5 grooves in the female rotor, is actually preferable to a $4 / 6$ configuration. In addition, deeper profiles for better displacement have been recently studied by Stosic et al. [22] by reducing the center distance between the rotors, which is a fixed geometric parameter in the present work.

The next section presents four patented profiles, along with a reference profile studied in detail in a former work [18], where specific details about the design method have been reported. Focusing on the male rotor, as highlighted in the following, all the frames are similar as regards the flat side. Thus, the comparison is fair because the variation in the rotor profile refers to the round side of the lobe.

\section{Rotor profile investigation}

This section presents the demonstrator profile [5], starting from the reference geometry of a twin-screw compressor investigated in a previous work [18], along with other four 
patented solutions [13-16]. In detail, the new rotor profiles are investigated as possible improvements in terms of inter-lobe area.

\subsection{Reference profile}

The demonstrator profile is a rotor generated ' $N$ ' profile [5]. This specific profile is chosen as the reference case, as formerly investigated [18]. The curves generating the lobe profile of the demonstrator are given on the male rotor for the most part. Actually, this rotor profile, as well as the others in the following, is differentiable in every point. In detail, the profile is divided into a few segments, as shown in Fig. 2a:

- the segment $\mathrm{A}_{1} \mathrm{~B}_{1}$ (in black in Fig. 2a) on the male profile is an arc of circumference with radius $r_{1}$. Its center lies on the line from $\mathrm{O}_{1}$ to $\mathrm{O}_{2}$, centers of the two rotors; the segment $\mathrm{A}_{2} \mathrm{~B}_{2}$ on the female profile is the corresponding conjugate;

- the segment $\mathrm{B}_{1} \mathrm{C}_{1}$ (in magenta in Fig. 2a) on the male profile is an arc of circumference with radius $r_{3}$. Its center lies on the line from $\mathrm{O}_{1}$ to $\mathrm{C}_{1}$; the segment $\mathrm{B}_{2} \mathrm{C}_{2}$ on the female profile is the corresponding conjugate;

- the segment $\mathrm{A}_{1} \mathrm{D}_{1}$ (in red in Fig. 2a) on the male profile is an arc of circumference with radius $r_{2}$. Its center lies on the line from $\mathrm{O}_{1}$ to $\mathrm{O}_{2}$; the segment $\mathrm{A}_{2} \mathrm{D}_{2}$ on the female profile is the corresponding conjugate;

- the segment $\mathrm{D}_{2} \mathrm{E}_{2}$ (in blue in Fig. 2a) on the female profile is an arc of circumference with radius $\mathrm{r}_{4}$. Its center lies on the line from $\mathrm{O}_{2}$ to $\mathrm{E}_{2}$; the segment $\mathrm{D}_{1} \mathrm{E}_{1}$ on the male profile is the corresponding conjugate.

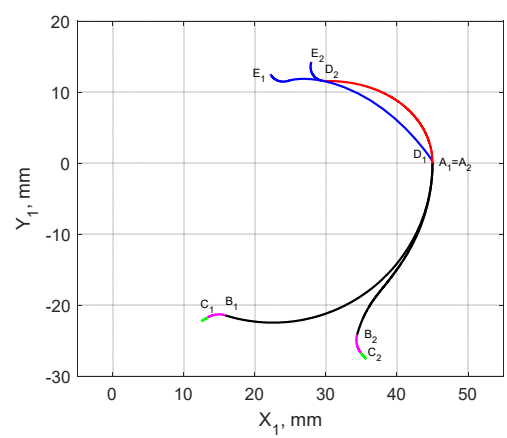

a)

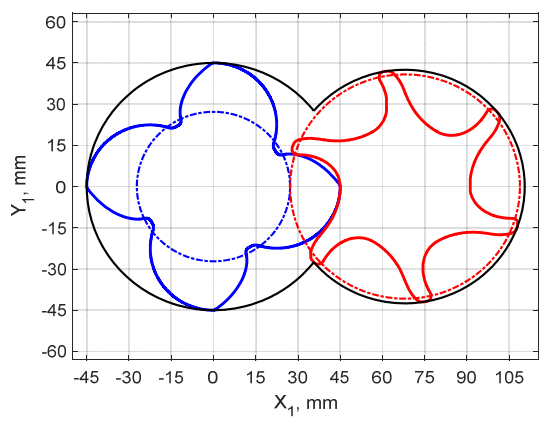

b)

Fig. 2. Contours (a) of male lobe and female groove based on the demonstrator frame [5] and plot (b) of the two rotors with the lobes shaped according to the demonstrator profile.

The main geometry of the compressor investigated in this paper is reported in Table 1. As regards the specific parameters for shaping the rotor, three values have been set: $r_{2}=1$ $\mathrm{mm}, \mathrm{r}_{3}=3 \mathrm{~mm}$ and $\mathrm{r}_{4}=2 \mathrm{~mm}$ [18]. In detail, $\mathrm{r}_{1}$ in segment $\mathrm{A}_{1} \mathrm{~B}_{1}$ results from the geometry construction. Differently from the original frame [5], the female lobe has been strengthened by maintaining the outer diameter constant for an angular range of $1.5^{\circ}$ (in green in Fig. 2a, on the right of $\mathrm{C}_{2}$ ). Such a feature is always included in the next profiles despite the specific generating curves [13-16].

\section{2 'P' profile}

The second profile case refers to the patent of Kasuya et al. [13], where an arc of parabola is introduced. In this case, the primary curves generating the lobe profiles are given on the female rotor for the most part. As shown in Fig. 3a, the profile is divided into a few segments: 
Table 1. Main geometry for the investigated compressor.

\begin{tabular}{cc}
\hline Lobe number of the male rotor & 4 \\
\hline Lobe number of the female rotor & 6 \\
\hline Outer diameter of the male rotor & $90 \mathrm{~mm}$ \\
\hline Outer diameter of the female rotor & $85 \mathrm{~mm}$ \\
\hline Inner diameter of the male rotor & $51 \mathrm{~mm}$ \\
\hline Inner diameter of the female rotor & $46 \mathrm{~mm}$ \\
\hline Wrap angle of the male rotor & $300^{\circ}$ \\
\hline Wrap angle of the female rotor & $200^{\circ}$ \\
\hline Center distance between the rotors & $68 \mathrm{~mm}$ \\
\hline Length of the rotors & $140 \mathrm{~mm}$ \\
\hline
\end{tabular}

- the segment $A_{2} B_{2}$ (in black in Fig. 3a) on the female profile is a portion of parabola whose axis lies on the line from $\mathrm{O}_{1}$ to $\mathrm{O}_{2}$, centers of the two rotors; the segment $\mathrm{A}_{1} \mathrm{~B}_{1}$ on the male profile is its corresponding conjugate;

- the segment $\mathrm{B}_{2} \mathrm{C}_{2}$ (in magenta in Fig. 3a) on the female profile is an arc of circumference with radius $\mathrm{r}_{3}$ P. Its center lies inside the line from $\mathrm{O}_{2}$ to $\mathrm{C}_{2}$; the segment $\mathrm{B}_{1} \mathrm{C}_{1}$ on the male profile is its corresponding conjugate;

- the segment $A_{1} D_{1}$ (in red in Fig. 3a) on the male profile is an arc of circumference with radius $\mathrm{r}_{2}$. Its center lies on the line from $\mathrm{O}_{1}$ to $\mathrm{O}_{2}$; the segment $\mathrm{A}_{2} \mathrm{D}_{2}$ on the female profile is its corresponding conjugate;

- the segment $\mathrm{D}_{2} \mathrm{E}_{2}$ (in blue in Fig. 3a) on the female profile is an arc of circumference with radius $r_{4 P}$. Its center lies on the line from $\mathrm{O}_{2}$ to $E_{2}$; the segment $\mathrm{D}_{1} \mathrm{E}_{1}$ on the male profile is its corresponding conjugate.

Comparing such ' $\mathrm{P}$ ' profile with the previous demonstrator, it is possible to realize that the main difference focuses on the round side of the male rotor. As a matter of fact, the flat side is the same, as well as the corresponding conjugate counterpart in the female groove.

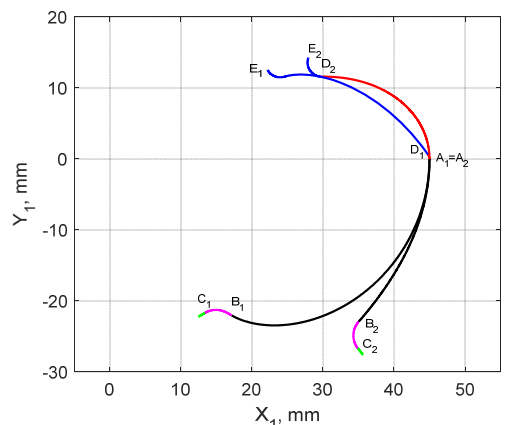

a)

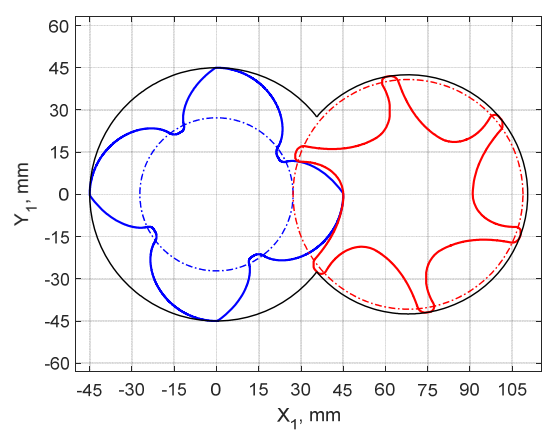

b)

Fig. 3. Contours (a) of male lobe and female groove based on the ' $\mathrm{P}$ ' frame [13] and plot (b) of the two rotors with the lobes shaped according to the 'P' profile. 
The main geometry for this ' $\mathrm{P}$ ' case is the one reported in Table 1. In detail, the same values of $r_{2}$ and $r_{4}$ introduced for the reference profile have been assumed for $r_{2 P}$ and $r_{4 P}$. The shape of the parabolic arc from $\mathrm{A}_{2}$ to $\mathrm{B}_{2}$ in Figs. $3 \mathrm{a}$ and $3 \mathrm{~b}$ results from the geometry construction after setting $\mathrm{r}_{3 \mathrm{P}}=2.904 \mathrm{~mm}$, which is the value of the radius of curvature of the segment $B_{2} C_{2}$ in the reference profile at point $C_{2}$. Actually, the radius $r_{3}$ is a degree of freedom. After ' $\mathrm{P}$ ' profile equation implementation in the MATLAB ${ }^{\circledR}$ environment, the plot in Fig. 3 b shows the new male and female rotors, along with the two pitch circumferences and the inner contour of the housing.

\section{3 'E’ profile}

The third profile case refers to the patent of Lee [14], where an arc of ellipse is introduced. Differently from the previous case, the primary curves generating the lobe profile are given on the male rotor for the most part, similarly to the demonstrator case. As shown in Fig. 4a, the profile is divided into a few segments:

- the segment $A_{1} B_{1}$ (in black in Fig. $4 a$ ) on the male profile is a quarter of ellipse. The focal points lie on the line from $\mathrm{O}_{1}$ to $\mathrm{O}_{2}$, centers of the two rotors, and point $\mathrm{B}_{1}$ lies on the pitch circumference [14]; the segment $\mathrm{A}_{2} \mathrm{~B}_{2}$ on the female profile is the corresponding conjugate;

- the segment $\mathrm{B}_{1} \mathrm{C}_{1}$ (in magenta in Fig. $4 \mathrm{a}$ ) on the male profile is an arc of circumference with radius $r_{3 E}$. Its center lies on the line from $\mathrm{O}_{1}$ to $\mathrm{C}_{1}$. Since point $\mathrm{B}_{1}$ lies on the pitch circumference [14], $\mathrm{r}_{3 \mathrm{E}}$ results from a specific frame and cannot be set arbitrarily; the segment $\mathrm{B}_{2} \mathrm{C}_{2}$ on the female profile is the corresponding conjugate;

- the segment $\mathrm{A}_{1} \mathrm{D}_{1}$ (in red in Fig. 4a) on the male profile is an arc of circumference with radius $r_{2 E}$. Its center lies on the line from $\mathrm{O}_{1}$ to $\mathrm{O}_{2}$; the segment $\mathrm{A}_{2} \mathrm{D}_{2}$ on the female profile is the corresponding conjugate;

- the segment $\mathrm{D}_{2} \mathrm{E}_{2}$ (in blue in Fig. 4a) on the female profile is an arc of circumference with radius $\mathrm{r}_{4 \mathrm{E}}$. Its center lies on the line from $\mathrm{O}_{2}$ to $\mathrm{E}_{2}$; the segment $\mathrm{D}_{1} \mathrm{E}_{1}$ on the male profile is the corresponding conjugate.

Comparing such ' $E$ ' profile with the previous two, it is possible to realize that the main difference focuses on the round side of the male rotor, as the flat side is the same. Similar considerations can be made for the female counterpart.

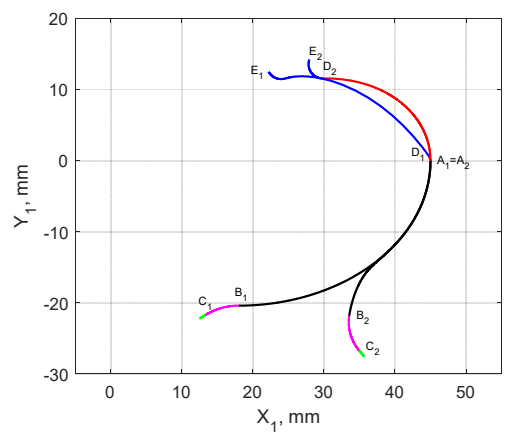

a)

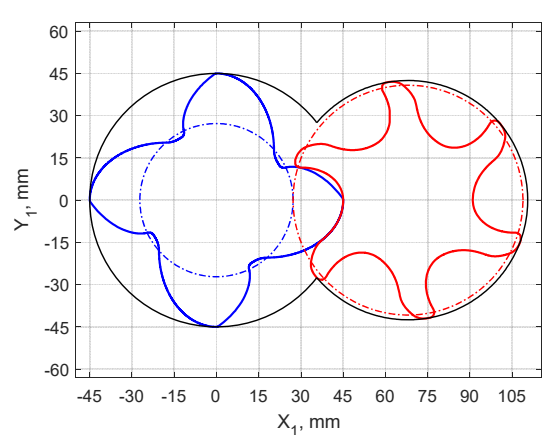

b)

Fig. 4. Contours (a) of male lobe and female groove based on the 'E' frame [14] and plot (b) of the two rotors with the lobes shaped according to the ' $E$ ' profile.

The main geometry is the one reported in Table 1 . In detail, the same values of $r_{2}$ and $r_{4}$ introduced for the reference profile have been assumed for $r_{2 \mathrm{E}}$ and $\mathrm{r}_{4 \mathrm{E}}$. The shape of the quarter of elliptic arc results from the geometry construction, as well as the value of $r_{3 E}$, which is not a degree of freedom, differently from the previous $r_{3 P}$ in the ' $P$ ' frame. After 
' $E$ ' profile equation implementation in the $M A T L A B{ }^{\circledR}$ environment, the plot in Fig. $4 \mathrm{~b}$ shows the new male and female rotors, along with the two pitch circumferences and the inner contour of the housing. In this case, thicker lobes in the female rotor compared to Figs. $3 \mathrm{~b}$ and $4 \mathrm{~b}$ can be immediately appreciated.

\section{4 'H' profile}

The fourth profile case refers to the patent of Chen [15], where an arc of hyperbola is introduced. Similarly to the 'P' frame, the primary curves generating the lobe profile are given on the female rotor for the most part, differently from the demonstrator and the ' $E$ ' profiles. As shown in Fig. 5a, the profile is divided into a few segments:

- the segment $\mathrm{A}_{2} \mathrm{~B}_{2}$ (in black in Fig. 5a) on the female profile is a portion of hyperbola whose axis lies on the line from $\mathrm{O}_{1}$ to $\mathrm{O}_{2}$, centers of the two rotors; the segment $\mathrm{A}_{1} \mathrm{~B}_{1}$ on the male profile is the corresponding conjugate;

- the segment $\mathrm{B}_{2} \mathrm{C}_{2}$ (in magenta in Fig. 5a) on the female profile is an arc of circumference with radius $\mathrm{r}_{3 \mathrm{H}}$. Its center lies inside the line from $\mathrm{O}_{2}$ to $\mathrm{C}_{2}$; the segment $\mathrm{B}_{1} \mathrm{C}_{1}$ on the male profile is the corresponding conjugate;

- the segment $A_{1} D_{1}$ (in red in Fig. 5a) on the male profile is an arc of circumference with radius $r_{2 H}$. Its center lies on the line from $\mathrm{O}_{1}$ to $\mathrm{O}_{2}$; the segment $\mathrm{A}_{2} \mathrm{D}_{2}$ on the female profile is the corresponding conjugate;

- the segment $\mathrm{D}_{2} \mathrm{E}_{2}$ (in blue in Fig. 5a) on the female profile is an arc of circumference with radius $\mathrm{r}_{4 \mathrm{H}}$. Its center lies on the line from $\mathrm{O}_{2}$ to $\mathrm{E}_{2}$; the segment $\mathrm{D}_{1} \mathrm{E}_{1}$ on the male profile is the corresponding conjugate.

Comparing such ' $\mathrm{H}$ ' profile with the previous demonstrator, ' $\mathrm{P}$ ' and ' $\mathrm{E}$ ' frames, the main difference concerns the round side of the male rotor, as the flat side is always the same.

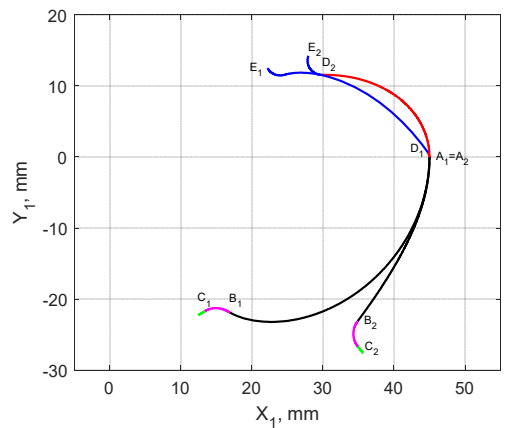

a)

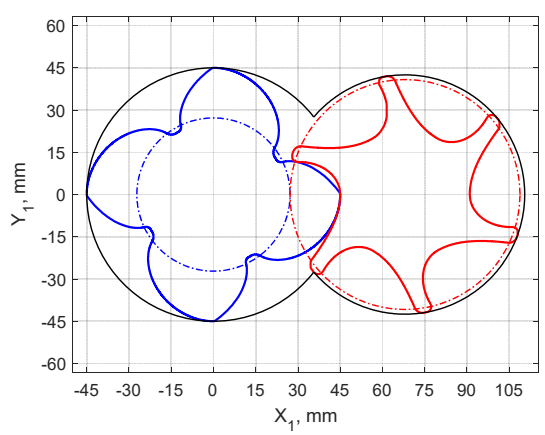

b)

Fig. 5. Contours (a) of male lobe and female groove based on the ' $H$ ' frame [15] and plot (b) of the two rotors with the lobes shaped according to the ' $\mathrm{H}$ ' profile.

According to the main geometry reported in Table 1, the same values of $r_{2}$ and $r_{4}$ introduced for the reference profile have been assumed for $\mathrm{r}_{2 \mathrm{H}}$ and $\mathrm{r}_{4 \mathrm{H}}$. The shape of the hyperbolic arc results from the geometry construction after setting $\mathrm{r}_{3 \mathrm{H}}=2.904 \mathrm{~mm}$, which is the value of the radius of curvature of the segment $\mathrm{B}_{2} \mathrm{C}_{2}$ of the reference profile at point $\mathrm{C}_{2}$. Actually, the radius $r_{3 \mathrm{H}}$ is a degree of freedom, like $\mathrm{r}_{3 \mathrm{P}}$ for the ' $\mathrm{P}$ ' profile. After ' $\mathrm{H}$ ' profile equation implementation in the MATLAB ${ }^{\circledR}$ environment, the plot in Fig. $5 \mathrm{~b}$ shows the new male and female rotors, along with the two pitch circumferences and the inner contour of the housing. 


\section{5 'S' profile}

The fifth profile case refers to the patent of Bammert [16]. Here, a straight line segment, tangent to two circumference arcs, is introduced instead of specific conic sections as adopted in the previous cases [13-15]. Indeed, the patent under consideration is a prior document compared to the others [13-15] and details an early 'Sigma' profile as reported by Stosic et al. [5]. Similarly to the 'P' and ' $H$ ' frames, the primary curves generating lobe and groove contours are given on the female rotor for the most part, differently from the demonstrator and the 'E' profiles. As shown in Fig. 6a, the profile is divided into a few segments:

- the segment $\mathrm{A}_{2} \mathrm{~B}_{2}$ (in black in Fig. 6a) on the female profile is an arc of circumference with radius $r_{1 S}$ whose center lies on the line from $\mathrm{O}_{1}$ to $\mathrm{O}_{2}$, centers of the two rotors; the segment $A_{1} B_{1}$ on the male profile is the corresponding conjugate;

- the segment $B_{2} C_{2}$ (in red in Fig. 6a) on the female profile is a section of straight line, which is tangent in $B_{2}$ to the previous circumference arc $A_{2} B_{2}$ and in $C_{2}$ to the next circumference arc $\mathrm{C}_{2} \mathrm{D}_{2}$; the segment $\mathrm{B}_{1} \mathrm{C}_{1}$ on the male profile is the corresponding conjugate;

- the segment $\mathrm{C}_{2} \mathrm{D}_{2}$ (in magenta in Fig. 6a) on the female profile is an arc of circumference with radius $r_{3}$. Its center lies inside the line from $\mathrm{O}_{2}$ to $\mathrm{D}_{2}$; the segment $\mathrm{C}_{1} \mathrm{D}_{1}$ on the male profile is the corresponding conjugate;

- the segment $A_{1} E_{1}$ (in red in Fig. 6a) on the male profile is an arc of circumference with radius $r_{2}$. Its center lies on the line from $\mathrm{O}_{1}$ to $\mathrm{O}_{2}$; the segment $\mathrm{A}_{2} \mathrm{E}_{2}$ on the female profile is the corresponding conjugate;

- the segment $\mathrm{E}_{2} \mathrm{~F}_{2}$ (in blue in Fig. 6a) on the female profile is an arc of circumference with radius $\mathrm{r}_{4 \mathrm{~S}}$. Its center lies on the line from $\mathrm{O}_{2}$ to $\mathrm{F}_{2}$; the segment $\mathrm{E}_{1} \mathrm{~F}_{1}$ on the male profile is the corresponding conjugate.

Comparing such 'S' profile with the previous demonstrator, 'P', 'E' and ' $\mathrm{H}$ ' frames, the main difference always concerns the round side of the male rotor, as the flat side is simply the same.

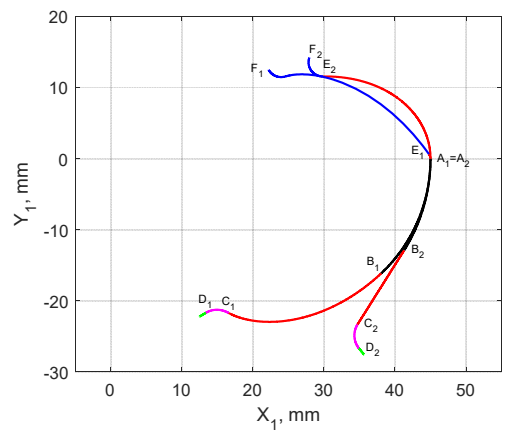

a)

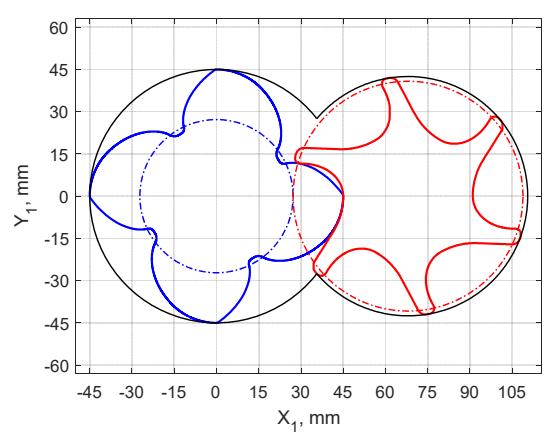

b)

Fig. 6. Contours (a) of male lobe and female groove based on the ' $S$ ' frame [16] and plot (b) of the two rotors with the lobes shaped according to the ' $S$ ' profile.

Based on the main geometry in Table 1 , the same values of $r_{2}$ and $r_{4}$ introduced for the reference profile have been assumed for $r_{2 S}$ and $r_{4 s}$. As regards the generating segments from $A_{2}$ to $D_{2}$ on the female rotor, $r_{1 S}=24.285 \mathrm{~mm}$, which is the value of the radius of curvature of the segment $A_{2} B_{2}$ of the reference profile at point $A_{2}$ and $r_{3 S}=2.904 \mathrm{~mm}$, which is the value of the radius of curvature of the segment $B_{2} C_{2}$ of the reference profile at point $C_{2}$. Length and slope of the segment from $B_{2}$ to $C_{2}$ result from the construction of this specific ' $S$ ' profile. Actually, both $r_{1 S}$ and $r_{3 S}$ are degrees of freedom, so the ' $S$ ' profile [16] 
seems to be more flexible than the previous ones [13-15]. After ' $S$ ' profile equation implementation in the MATLAB ${ }^{\circledR}$ environment, the plot in Fig. 6 b shows the new male and female rotors, along with the two pitch circumferences and the inner contour of the housing.

\section{Inter-lobe areas and other considerations}

The previous paragraphs, focusing on specific patented profiles, have introduced the geometric construction of different rotor shapes and qualitatively compared them with the reference case. All the five profile cases have the same shape for the flat side of the male rotor profile and the corresponding female conjugate. Indeed, other patented profiles use portions of conic sections. As an example, arcs of parabola are used by Hough et al. [23], but the flat side of the resulting male rotor profile differs from the ones presented in the previous section, where the flat side of the male rotor always has the same shape. Thus, the comparison of the five cases under investigation is fully fair.

Referring to each specific profile, the inter-lobe area evolution has been calculated based on the energy method, whose application to gear pumps for fluid power applications is widely reported in the literature [24-26]. In detail, according to the calculations resulting from the geometric approach adopted in a previous work [18], Table 2 reports the inter-lobe areas for the analyzed cases. After comparing the results, the ' $E$ ' profile is a very interesting solution in order to increase the volume displacement of the compressor. As a matter of fact, an improvement of around 3\% compared to the reference case seems to be possible. On the other hand, slight reductions of the inter-lobe area can be appreciated for the other three profiles ('P', 'H' and 'S'). In detail, they are less than $1 \%$, so preliminary considerations based on volumetric improvements may be misleading and should be revised according to further analyses of the twin-screw machine. In particular, the results in Table 2 are limited to the specific size reported in Table 1, without investigating possible improvements arising from a parametric analysis on profile parameters as formerly proposed by Bergadano et al. [18]. Nevertheless, the superiority of the ' $\mathrm{H}$ ' profile in terms of volume displacement, as reported elsewhere [5], cannot be confirmed here, as three solutions seem to be better than the ' $\mathrm{H}$ ' design, limited to this case study and the related calculation hypotheses.

Table 2. Maximum value of the inter-lobe area.

\begin{tabular}{cc}
\hline Reference profile & $995.1 \mathrm{~mm}^{2}$ \\
\hline 'P' profile & $985.9 \mathrm{~mm}^{2}$ \\
\hline 'E' profile & $1024.9 \mathrm{~mm}^{2}$ \\
\hline 'H' profile & $990.1 \mathrm{~mm}^{2}$ \\
\hline 'S' profile & $992.5 \mathrm{~mm}^{2}$ \\
\hline
\end{tabular}

Fig. 7 shows another geometric result, as previously anticipated when introducing the ' $E$ ' profile. The difference in the circular lobe thickness between the patented profiles [1316] and the demonstrator is reported as a function of the male/female rotor radius. Looking at the results, only the ' $\mathrm{E}$ ' profile presents less thick lobes for the male rotor and thicker lobes for the female rotor, compared to the reference case, differently from ' $\mathrm{P}$ ', ' $\mathrm{H}$ ' and ' $\mathrm{S}$ ' profiles. 
These results related to both inter-lobe areas and lobe thickness are consistent with the studies by Stosic et al. [5, 27]. In particular, the lower thickness of the male lobe according to the ' $E$ ' design should not affect its mechanical strength. Of course, the higher the volume displacement, the larger the flow rate delivery, though attention should be paid to the fluid leakages. On one hand, considering the flat side of the male lobe is always the same for the analyzed profiles [13-16], as well as for the female counterpart, no variations can be calculated for the blow-hole [18], which is the same for all the cases here investigated after radii $r_{2}$ and $r_{4}$ have been set. On the other hand, attention should be also paid to the leakage paths across the sealing line. As a matter of fact, higher volume displacements usually result in longer sealing lines $[5,18,27]$ and the ' $E$ ' profile investigated in this study is no exception. Actually, the calculated length of the sealing line for the ' $E$ ' profile is $4.65 \%$ greater than the reference profile and $5.76 \%$ greater than the ' $\mathrm{H}$ ' profile, which has the shorter sealing line limited to the investigated cases. In addition, when calculating the ratio between the length of the sealing line and the inter-lobe area, the highest value occurs precisely for the ' $E$ ' profile $\left(120.4 \mathrm{~m}^{-1}\right)$ and the lowest for the ' $\mathrm{H}$ ' profile $\left(117.9 \mathrm{~m}^{-1}\right)$, suggesting that a simple geometric comparison may be not sufficient to select the proper profile.

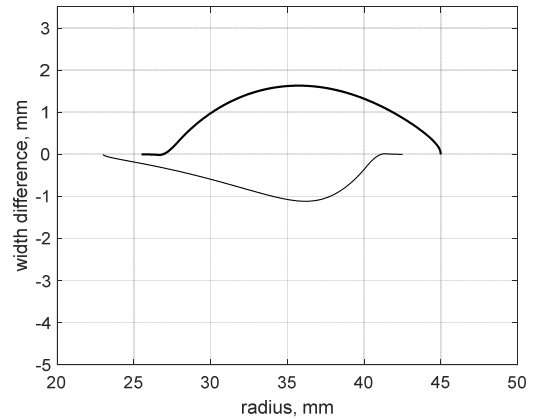

a)

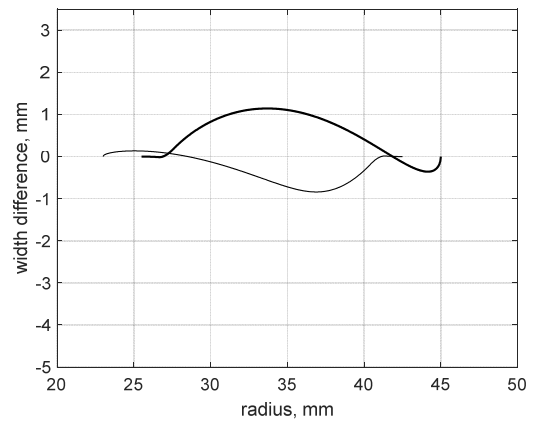

c)

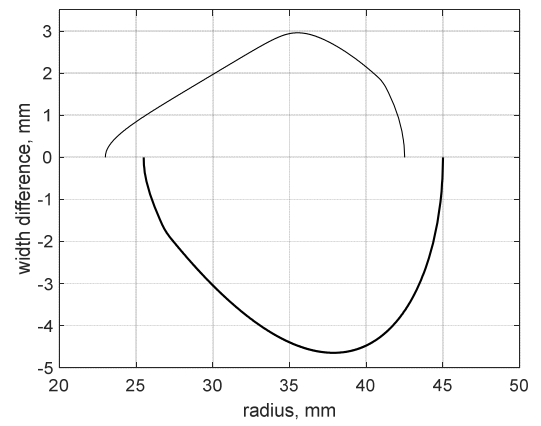

b)

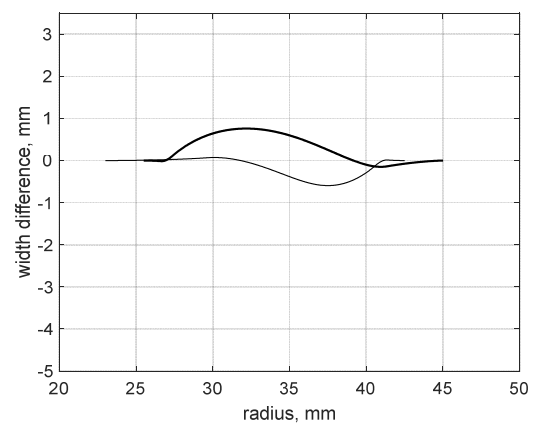

d)

Fig. 7. Differences in lobe thickness between the ' $P$ ' and the demonstrator profiles (a), the ' $E$ ' and the demonstrator profiles (b), the ' $\mathrm{H}$ ' and the demonstrator profiles (c), the ' $\mathrm{S}$ ' and the demonstrator profiles (d). Thick traces refer to the male lobe and thin traces refer to the female lobe.

\section{Conclusions}

This work has presented a comparison among some solutions for profiling the rotor contours of twin-screw compressors, compared to a reference case, previously analysed in detail [18]. Four patented profiles have been considered in this work as case studies, in 
order to highlight the better frame for the higher inter-lobe area, i.e. the higher volume displacement. The profile adopting an elliptic segment is the preferable solution for such a purpose, though limited to the current case study. However, other considerations for a broader context should be made as regards the flow rate delivery, with particular reference to the leakage paths. As a matter of fact, a mathematical modelling for performance calculation of screw compressor processes [2] is really necessary to understand both the strong and weak points of one profile over another.

\section{References}

1. A. Giuffrida, Applied Thermal Engineering 93 (2016), https://doi.org/10.1016/j.applthermaleng.2015.10.023

2. N. Stosic, I.K. Smith, A. Kovacevic, E. Mujic, International Journal of Fluid Machinery and Systems 4 (2011), https://doi.org/10.5293/IJFMS.2011.4.2.271

3. H.H. Patel, V.J. Lakhera, Proceedings of the Institution of Mechanical Engineers Part E: Journal of Process Mechanical Engineering 234 (2020), https://doi.org/10.1177/0954408919869534

4. F.L. Litvin, P.H. Feng, Mechanism and Machine Theory 32 (1997), https://doi.org/10.1016/S0094-114X(96)00036-5

5. N. Stosic, I. Smith, A. Kovacevic, Screw compressors - Mathematical modelling and performance calculation, Springer-Verlag, 2005

6. D. Zaytsev, C.A. Infante Ferreira, International Journal of Refrigeration 28 (2005), https://doi.org/10.1016/j.ijrefrig.2004.12.006

7. Y.R. Wu, H.F. Fong, Mechanism and Machine Theory 43 (2008), https://doi.org/10.1016/j.mechmachtheory.2007.05.008

8. N. Stosic, Proceedings of the Institution of Mechanical Engineers Part C: Journal of $\begin{array}{llll}\text { Mechanical Engineering } & 212 & \text { Science }\end{array}$ https://doi.org/10.1243/0954406981521556

9. Y.R. Wu, Z.H. Fong, Mechanism and Machine Theory 44 (2009), https://doi.org/10.1016/j.mechmachtheory.2008.02.013

10. L.B. Schibbye, U.S. Patent 3423017 (21 January 1969)

11. L.B. Schibbye, U.S. Patent 4140445 (20 February 1979)

12. A. Astberg, U.S. Patent No. 4435139 (6 March 1984)

13. Kasuya, K., Fujiwara, M., Matsunaga, T., Imai, M., Takahashi, Y. U.S. Patent 4406602 (27 September 1983)

14. H.T. Lee, U.S. Patent 4890992 (2 January 1990)

15. C.H. Chen, U.S. Patent 5454701 (3 October 1995)

16. K. Bammert, U.S. Patent 4350480 (21 September 1982)

17. G. Weih, U.S. Patent 2017/0045050 (16 February 2017)

18. E. Bergadano, A. Giuffrida, U. Gorini, C. Tornatora, A study on the main geometric characteristics of twin-screw compressors, In AIP Conference Proceedings 2191 (2019), https://doi.org/10.1063/1.5138751

19. A. Nikolov, A. Brümmer, Impact of different clearance heights on the operation of a water-flooded twin-screw expander-experimental investigations based on indicator diagrams, In IOP Conf. Series: Materials Science and Engineering 425 (2018), https://doi:10.1088/1757-899X/425/1/012008 
20. Y. Lu, A. Kovacevic, M. Read, Normal rack grid generation method for screw machines with large helix angles, In IOP Conf. Series: Materials Science and Engineering 604 (2019), https://doi:10.1088/1757-899X/604/1/012011

21. D.H. Rowinski, Y. Li, K. Bansal, Investigations of Automatic Meshing in Modeling a Dry Twin Screw Compressor, In International Compressor Engineering Conference 2018, https://docs.lib.purdue.edu/icec/2621

22. N. Stosic, I. Smith, A. Kovacevic, Improving Screw Compressor Displacement and Efficiency by Increasing the Rotor Profile Depth, In IOP Conf. Series: Materials Science and Engineering 604 (2019), https://iopscience.iop.org/article/10.1088/1757899X/604/1/011012

23. D. Hough, S.J. Morris, A.D. Barber. U.S. Patent 4636156 (13 January 1987)

24. J. Ivantysyn, M. Ivantysynova, Hydrostatic Pumps and Motors, Academia Books International, 2002

25. N.H. Manring, S.B. Kasaragadda, Journal of Dynamic Systems, Measurement, and Control 125 (2003), https://doi.org/10.1115/1.1592193

26. R.S. Devendran, A. Vacca, Mechanism and Machine Theory 218 (2017), https://doi.org/10.1016/j.mechmachtheory.2016.10.001

27. N. Stosic, I.K. Smith, A. Kovacevic, Applied Thermal Engineering 23 (2003), https://doi.org/10.1016/S1359-4311(03)00059-0 